International Journal of Pure and Applied Mathematics

Volume 96 No. 2 2014, 213-228

ISSN: 1311-8080 (printed version); ISSN: 1314-3395 (on-line version)

url: http://www.ijpam.eu

doi: http://dx.doi.org/10.12732/ijpam.v96i2.5

ijpam.eu

\title{
NUMERICAL STUDY OF NATURAL CONVECTION IN POROUS SQUARE ENCLOSURE NON-UNIFORMLY HEATED FROM THE PARTITIONS
}

\author{
Paweena Khansila ${ }^{1}$, Supot Witayangkurn ${ }^{2}$ \\ ${ }^{1,2}$ Department of Mathematics \\ Faculty of Science \\ Khon Kaen University \\ Khon Kaen, 40002, THAILAND \\ ${ }^{1,2}$ Centre of Excellence in Mathematics \\ CHE, Si Ayutthaya Rd., Bangkok 10400, THAILAND
}

\begin{abstract}
Numerical study has been performed to investigate the effects of location and height for the partitions located on the bottom wall of a square enclosure filled with porous media. This study starts considering the simplest enclosure with two partitions. The partitions are non-uniformly heated. The left and the top wall are cooled while the right and the bottom wall are adiabatic well. The location and height of two partitions are considered. The interested parameters are Darcy number $(D a)$ from $10^{-5}$ to $10^{-1}$, the value of Rayleigh number $(R a)$ is fixed at $10^{5}$ and the Prandtl number $(P r)$ is 0.71 . The results are presented in forms of streamlines, isotherms and heatlines. It can be found that the flow field is single cell when the height of the partitions is less than 0.5. The flow field and heat transfer increase when the value of Darcy number is increased.
\end{abstract}

AMS Subject Classification: 74S05, 76D05, 76R10, 76S05, 80A20

Key Words: natural convection, non-uniformly temperature, porous media, partition enclosure

Received: April 11, 2014

(c) 2014 Academic Publications, Ltd. url: www.acadpubl.eu 


\section{Introduction}

In many studies, natural convection heat transfer of fluid-saturated porous medium is an important problem in engineering. Applications of porous media can be seen in geophysic problems, solar collectors, heat exchangers, grain storage, nuclear reactor and so on. Detailed reviews of subject of porous media can be found in the recent books of Nield and Bejan [1], and Ingham and Pop $[2]$.

The investigations of natural convection for different enclosures filled with porous media are available in reviews. Based on knowledge for the application of engineering in flow field, temperature distribution and heat transfer can be used to design high efficient thermal systems. In the past year, most reviews focused on investigation of natural convection in the enclosure which can be classified into three groups: (a) general enclosures without fin or partition [4][9],(b) enclosures with fin or partition [10]-[16] and (c) other shapes of enclosure [17]-[18]. Furthermore, the studies of natural convection are very limited for cavities filled with porous media.

Aydin et al.[4] studied natural convection in the rectangular enclosures heated from one side and cooled from the ceiling and the effects of Rayleigh number and different aspect ratios in enclosure. Basak et al.[5] investigated numerical results of natural convection in porous square and the effects of various thermal boundary conditions. Bilgen and Yedder[6] performed the numerical of natural convection in an enclosure which had a vertical active wall with all the other walls were insulated. The equally divided active sidewall was heated and cooled with sinusoidal temperature profiles. Varol et al.[7] studied numerical analysis of natural convection for a porous enclosure with sinusoidally temperature profile on the bottom wall. Varol et al. [8] considered natural convection heat transport using heatline method in porous non-isothermally heated triangular cavity. Khansila and Witayangkurn[9] studied the visualization of natural convection in porous enclosure by sinusoidally temperature on the one side. Oztop et al.[10],[13] and [16] considered natural convection in enclosure or porous enclosure with solid fin and partition attached to wall. Bilgen[11] investigated the natural convection in cavities with thin fin on the hot wall and considered different of lengths of thin fin in enclosure. Nada[12] performed heat transfer and fluid flow characteristics in horizontal and vertical narrow enclosures with heated rectangular was finned base plate. Ben-Nakhi and Chamkha[14] studied conjugate natural convection in enclosure with inclined thin fin of different lengths. Kahveci and Oztuna[15] considered MHD natural convection flow and heat transfer in a laterally wall was heated partition enclosure and solved 


\section{Nomenclature}

$c_{p}$

$D a$

$g$

$h$

$H$

$k$

K

$l$

$L$

$p$

$P$

$\operatorname{Pr}$

$R a$

$s$

T

$u, v$

$U, V$

$x, y$

$X, Y$

Greek symbols

$\alpha$

$\beta$

$\gamma$

$\nu$

$\psi$

$\Psi$

$\rho$

$\theta$

$\Phi$

subscripts

C

$H$ heat capacity $\left(\mathrm{Jkg}^{-1} \mathrm{~W}^{-1}\right)$

Darcy number

gravitational acceleration $\left(\mathrm{ms}^{-2}\right)$

heat function

height of the enclosure $(\mathrm{m})$

thermal conductivity $\left(\mathrm{Wm}^{-1} \mathrm{~K}^{-1}\right)$

permeability of porous medium $\left(\mathrm{m}^{2}\right)$

height of the partition $(\mathrm{m})$

length of the enclosure $(\mathrm{m})$

pressure $(\mathrm{Pa})$

dimensionless pressure

Prandtl number

Rayleigh number

length between two partitions (m)

temperature $(\mathrm{K})$

velocity components $\left(\mathrm{ms}^{-1}\right)$

dimensionless velocity components

Cartesian coordinates $(\mathrm{m})$

dimensionless Cartesian coordinates

thermal diffusivity $\left(\mathrm{m}^{2} \mathrm{~s}^{-1}\right)$

volumetric coefficient of thermal expansion $\left(\mathrm{K}^{-1}\right)$

penalty parameter

kinematic viscosity $\left(\mathrm{m}^{2} \mathrm{~s}^{-1}\right)$

stream function

dimensionless stream function

fluid density $\left(\mathrm{kg} \mathrm{m}^{-3}\right)$

dimensionless temperature

dimensionless heat function

cold

hot

problem by using the polynomial differential quadrature method. Bhanja and Kundu[17] studied thermal analysis of a construct T-shaped porous fin with radiation effects. Finally, Hussain et al.[18] investigated influence of presence of inclined center baffle and corrugation frequency on natural convection in square enclosure. 
Heatline technique is an important method to visualize heat transport in enclosures filled clear fluid-saturated porous media. The isotherms are used to show the temperature distribution in a domain. Streamline present the flow field in the enclosure. However, it is easy to realize the direction and intensity of the heat transfer particularly in convection problems which the path of heat flux is perpendicular and the isotherm due to convection effect.

Thus, the purpose of this research is to study the results of natural convection in a porous enclosure when two partitions of enclosure are non-uniformly heated. The effects of location and height of the partitions are considered for the various Darcy numbers. Fluid flow field, thermal field and heat transfer are presented through the streamlines, isotherms and heatlines, respectively.

\section{Definition of Physical Model}

The physical model of the two-dimensional system and boundary conditions are shown in figure 1. In this figure, the partitions are attached at the bottom wall, and the enclosure is a square with $\mathrm{H}=\mathrm{L}$. It is heated from two partitions and the bottom and the right wall are insulated while the top and the left walls are cooled. Two partitions are non-uniformly heated and the temperatures of partitions are given by $T(y)=T_{C}+\left(T_{H}-T_{C}\right) \sin \left(\frac{\pi y}{L}\right)$ and $T(x)=T_{C}+\left(T_{H}-\right.$ $\left.T_{C}\right) \sin \left(\frac{\pi x}{L}\right)$. 


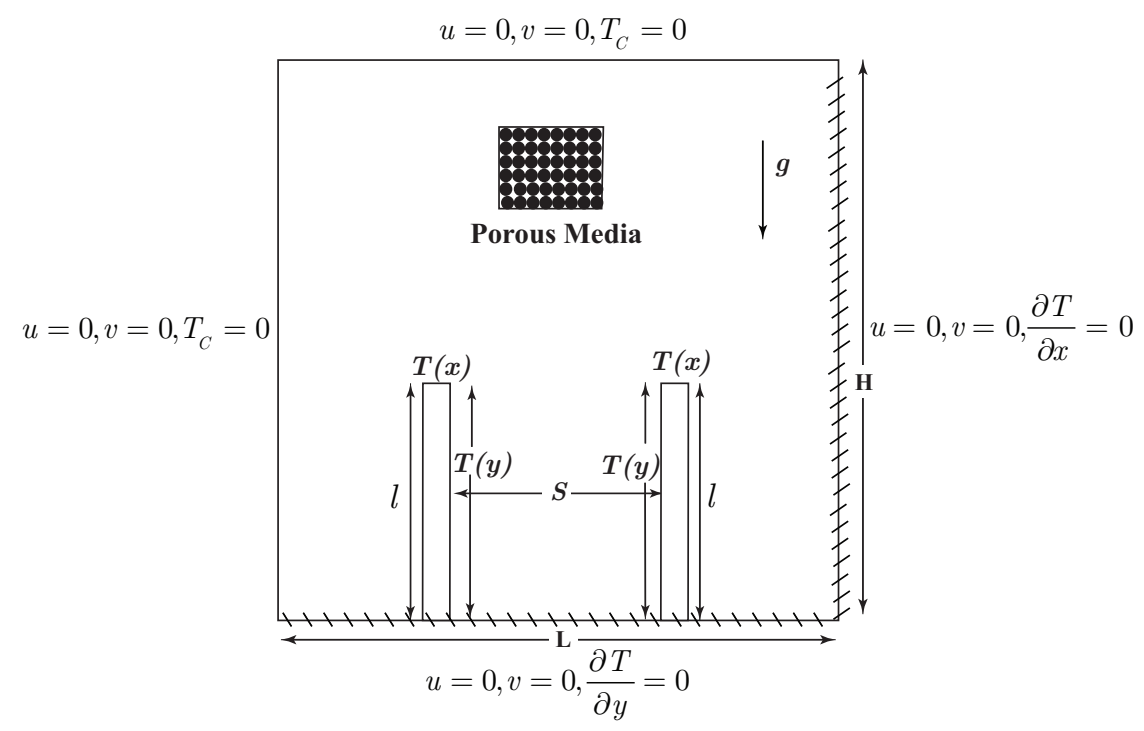

Figure 1: Physical model and coordinate system of a square enclosure filled with a porous media

\section{Governing Equation}

\subsection{Equations of Natural Convection}

The governing equation of natural convection in a square enclosure filled with a porous media consists the mass conservation equation, the momentum equation and the energy equation can be written as,

$$
\begin{aligned}
\frac{\partial u}{\partial x}+\frac{\partial v}{\partial y} & =0 \\
u \frac{\partial u}{\partial x}+v \frac{\partial u}{\partial y} & =-\frac{1}{\rho} \frac{\partial p}{\partial x}+\nu\left(\frac{\partial^{2} u}{\partial x^{2}}+\frac{\partial^{2} u}{\partial y^{2}}\right)-\frac{\nu}{K} u \\
u \frac{\partial v}{\partial x}+v \frac{\partial v}{\partial y} & =-\frac{1}{\rho} \frac{\partial p}{\partial y}+\nu\left(\frac{\partial^{2} v}{\partial x^{2}}+\frac{\partial^{2} v}{\partial y^{2}}\right)-\frac{\nu}{K} v+g \beta\left(T-T_{C}\right) \\
u \frac{\partial T}{\partial x}+v \frac{\partial T}{\partial y} & =\alpha\left(\frac{\partial^{2} T}{\partial x^{2}}+\frac{\partial^{2} T}{\partial y^{2}}\right)
\end{aligned}
$$


The form of stream function $\psi$ defined as,

$$
u=\frac{\partial \psi}{\partial y}, v=-\frac{\partial \psi}{\partial x} .
$$

Dimensionless variables are defined as follow,

$$
\begin{gathered}
X=\frac{x}{L}, \quad Y=\frac{y}{L}, \quad U=\frac{u L}{\alpha}, \quad V=\frac{v L}{\alpha}, \quad \Psi=\frac{\psi}{\alpha}, \quad \operatorname{Pr}=\frac{\nu}{\alpha}, \\
D a=\frac{K}{L^{2}}, \quad P=\frac{p L^{2}}{\rho \alpha^{2}}, \quad R a=\frac{g \beta \Delta T L^{3}}{\nu \alpha}, \quad \theta=\frac{T-T_{C}}{T_{H}-T_{C}} .
\end{gathered}
$$

Using dimensionless variables in Eqs. (5) and (6) reduce to Eqs.(1)-(4) which they can be written the forms of dimensionless equation as follow,

$$
\begin{aligned}
\frac{\partial^{2} \Psi}{\partial X^{2}}+\frac{\partial^{2} \Psi}{\partial Y^{2}} & =\frac{\partial U}{\partial Y}-\frac{\partial V}{\partial X} \\
U \frac{\partial U}{\partial X}+V \frac{\partial U}{\partial Y} & =-\frac{\partial P}{\partial X}+\operatorname{Pr}\left(\frac{\partial^{2} U}{\partial X^{2}}+\frac{\partial^{2} U}{\partial Y^{2}}\right)-\frac{\operatorname{Pr}}{D a} U \\
U \frac{\partial V}{\partial X}+V \frac{\partial V}{\partial Y} & =-\frac{\partial P}{\partial Y}+\operatorname{Pr}\left(\frac{\partial^{2} V}{\partial X^{2}}+\frac{\partial^{2} V}{\partial Y^{2}}\right)-\frac{\operatorname{Pr}}{D a} V+\operatorname{RaPr} \theta \\
U \frac{\partial \theta}{\partial X}+V \frac{\partial \theta}{\partial Y} & =\frac{\partial^{2} \theta}{\partial X^{2}}+\frac{\partial^{2} \theta}{\partial Y^{2}}
\end{aligned}
$$

In this study, we use the penalty finite element method where the pressure $(P)$ is eliminated by a penalty parameter $(\gamma)$ and the incompressibility criteria given by Eq. (1) which result as

$$
P=-\gamma\left(\frac{\partial U}{\partial X}+\frac{\partial V}{\partial Y}\right)
$$

The values of $\gamma$ that yield consistent solutions are $10^{7}[3]$. Using Eqs. (11) , the momentum balance Eqs. (8) and (9) reduce to

$$
\begin{aligned}
& U \frac{\partial U}{\partial X}+V \frac{\partial U}{\partial Y}=\gamma \frac{\partial}{\partial X}\left(\frac{\partial U}{\partial X}+\frac{\partial V}{\partial Y}\right)+\operatorname{Pr}\left(\frac{\partial^{2} U}{\partial X^{2}}+\frac{\partial^{2} U}{\partial Y^{2}}\right)-\frac{\operatorname{Pr}}{D a} U \\
& U \frac{\partial V}{\partial X}+V \frac{\partial V}{\partial Y}=\gamma \frac{\partial}{\partial Y}\left(\frac{\partial U}{\partial X}+\frac{\partial V}{\partial Y}\right)+\operatorname{Pr}\left(\frac{\partial^{2} V}{\partial X^{2}}+\frac{\partial^{2} V}{\partial Y^{2}}\right)-\frac{\operatorname{Pr}}{D a} V+\operatorname{RaPr} \theta
\end{aligned}
$$

Heat function in the problem of natural convection can be defined as[8]

$$
-\frac{\partial h}{\partial x}=\rho c_{p} v\left(T-T_{C}\right)-k \frac{\partial T}{\partial y},
$$




$$
\frac{\partial h}{\partial y}=\rho c_{p} u\left(T-T_{C}\right)-k \frac{\partial T}{\partial x}
$$

The dimensionless variable of heat function is $\Phi=\frac{h}{k\left(T_{H}-T_{C}\right)}$, we thus obtain that dimensionless equations as

$$
\begin{aligned}
-\frac{\partial \Phi}{\partial X} & =V \theta-\frac{\partial \theta}{\partial Y}, \\
\frac{\partial \Phi}{\partial Y} & =U \theta-\frac{\partial \theta}{\partial X} .
\end{aligned}
$$

For the equation of heat function is obtained as the solution of the Poisson differential equation,

$$
\frac{\partial^{2} \Phi}{\partial X^{2}}+\frac{\partial^{2} \Phi}{\partial Y^{2}}=\frac{\partial(U \theta)}{\partial Y}-\frac{\partial(V \theta)}{\partial X}
$$

\subsection{Boundary Condition}

The boundary conditions of this study are shown in Fig 1. In this model, $u=v=0$ for all solid boundaries of square enclosure and the partitions. On the left and the top wall $T_{C}=0$; on the right wall $\frac{\partial T}{\partial x}=0$; on the bottom wall $\frac{\partial T}{\partial y}=0$; on the partition are non-uniformly heated. For heat function, all sides of the enclosure are $\frac{\partial \Phi}{\partial n}=0$, where $n$ denotes the normal direction on a plane.

\section{Result and Discussion}

In this study, the numerical results are investigated to show the effects of natural convection in a square enclosure filled with a porous media when the partitions non-uniformly heated and they are attached at the bottom wall. The visualization for the streamlines, isotherms and heatlines contours for various location values of the partitions, height of two partitions, and the Darcy number $(D a)$ are reported and discussed. For all cases, the Darcy number $(D a)$ is varied from $10^{-5}$ to $10^{-1}$, and the value of Rayleigh number $(R a)$ is taken as $10^{5}$. All results are computed for Prandtl number $P r=0.71$, and the thickness of two partitions 
are fixed at 0.05. In addition, the effects of flow field, temperature distribution and heat transfer are presented in the terms of streamlines, isotherms and heatlines, respectively.

Figure 2(a)-2(c) illustrate the streamlines(left), isotherms(center) and heatlines(right) contours of the numerical results for various $D a=10^{-5}-10^{-1}, R a=$ $10^{5}, s=0.2$, and the heights of two partitions are 0.2. As can be seen in the Figure 2(a), double cells of streamlines rotate the different directions which the bigger cell rotates in counter clockwise direction but the smaller cell rotates in clockwise direction. For streamlines of Figure 2(b)-2(c), it can be seen that single cell rotates in counter clockwise direction. The contours of streamlines usually are in the form of an ellipsoidal cell but they are distorted by two partitions. When the value of Darcy number is increased, the maximum value of streamlines increases and magnitude of cell expands close to the walls. The contours of isotherms are smooth and monotonic. It is also observed that isotherms are distributed from two partitions into the insulated walls. When two partitions are heated, we can see that the temperature distribution of the region between two partitions are the same. Moreover, the contours of isotherms between the cooled walls have greater curvature and the contours dispersing to the right vertical wall are more dense when the value of Darcy number is increased. The top of two partitions is hottest. For heatlines in Figure 2, it can be seen that all visualizations of the heatlines are similar to the streamlines but some contours disperse toward the walls. Both absolute maximum and minimum heatlines values are increased with increasing Darcy number. The maximum heatlines value is also presented at the center of the left cell. 

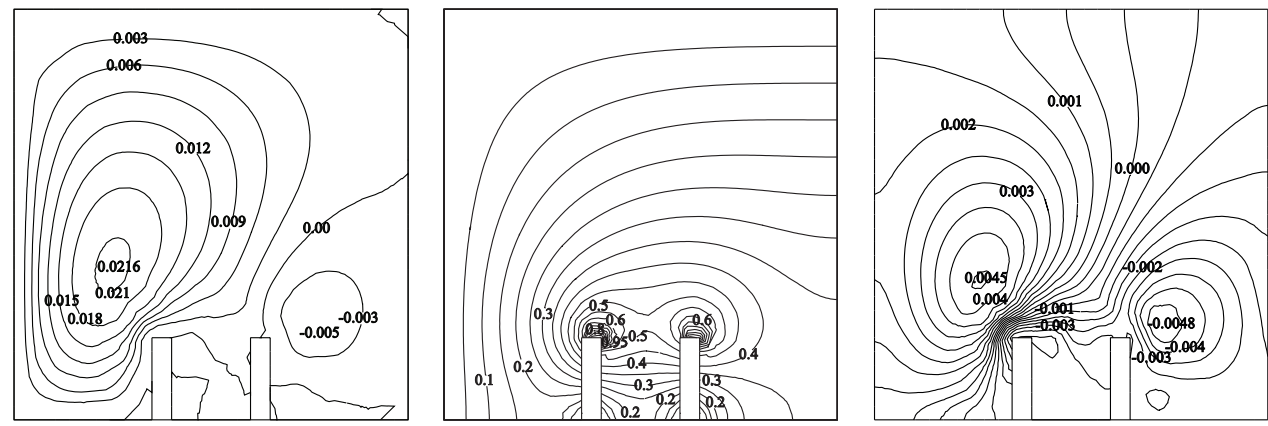

(a)
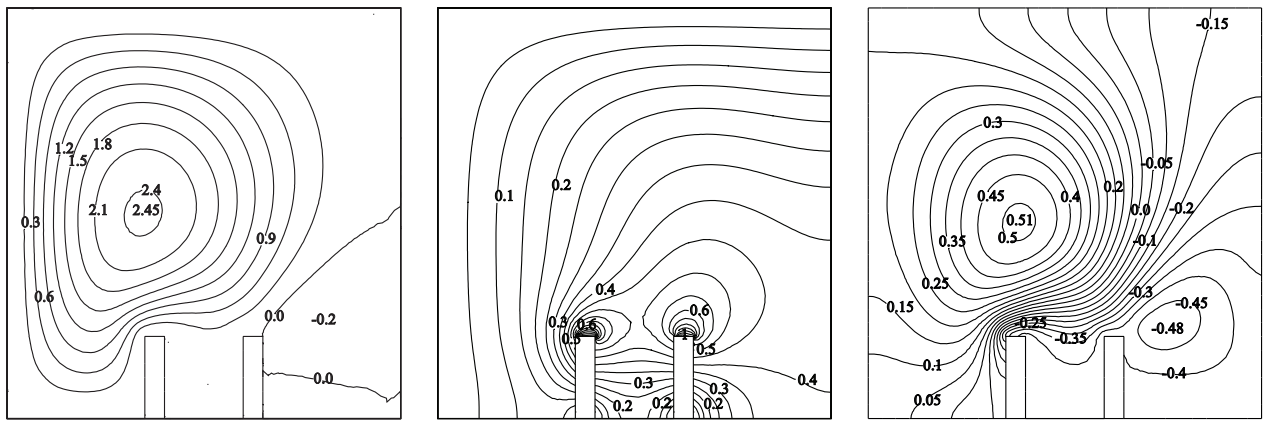

(b)
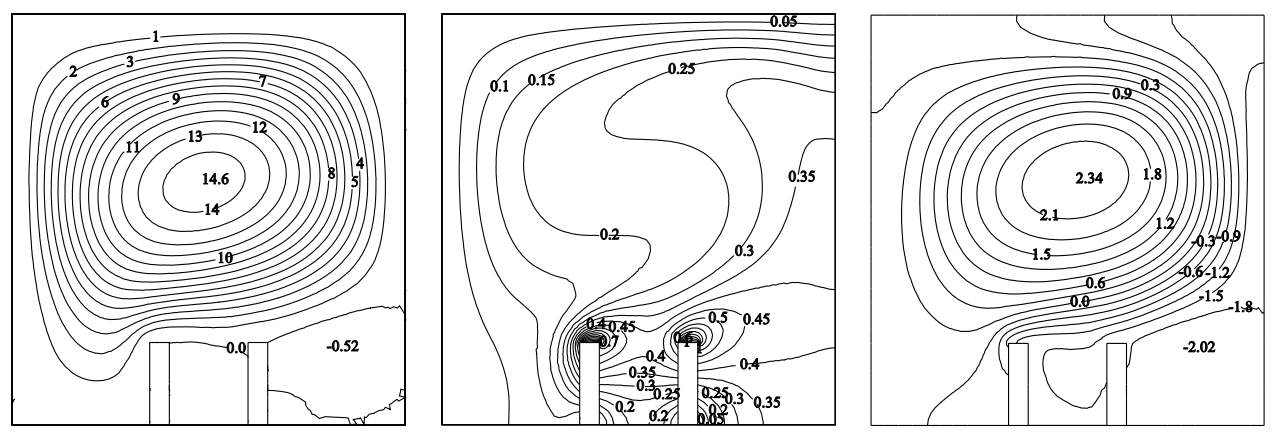

(c)

Figure 2: Streamlines(left), isotherms(center), heatlines(right) for $R a=$ $10^{5}, \mathrm{~s}=0.2$ and $l=0.2 ; D a=10^{-5}(\mathrm{a}), D a=10^{-3}(\mathrm{~b}), D a=10^{-1}(\mathrm{c})$

Figure 3(a)-3(c) illustrate the streamlines(left), isotherms(center) and heatlines(right) contours of the numerical results for various $D a=10^{-5}-10^{-1}, R a=$ $10^{5}, s=0.2$, and the heights of two partitions are 0.8. As seen from figure, dou- 

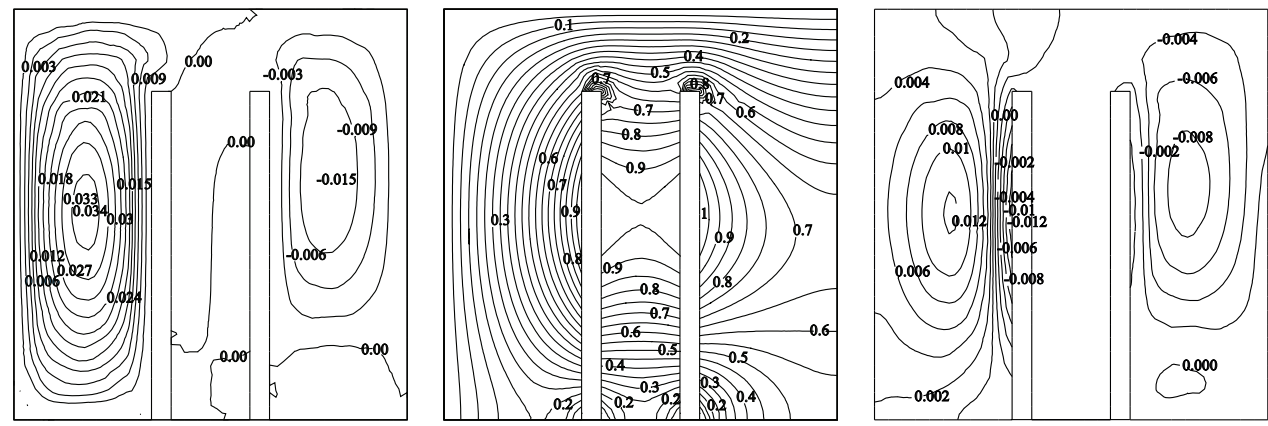

(a)
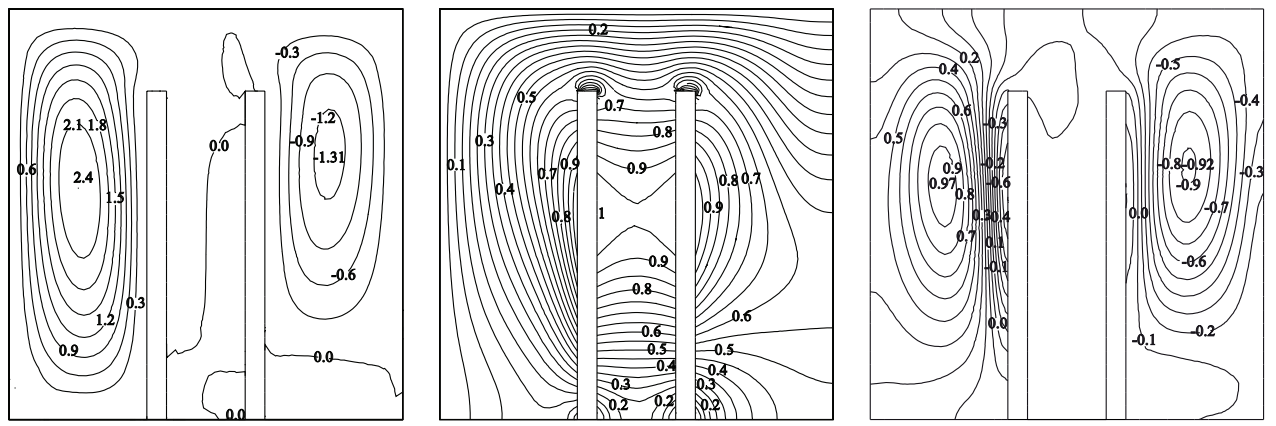

(b)
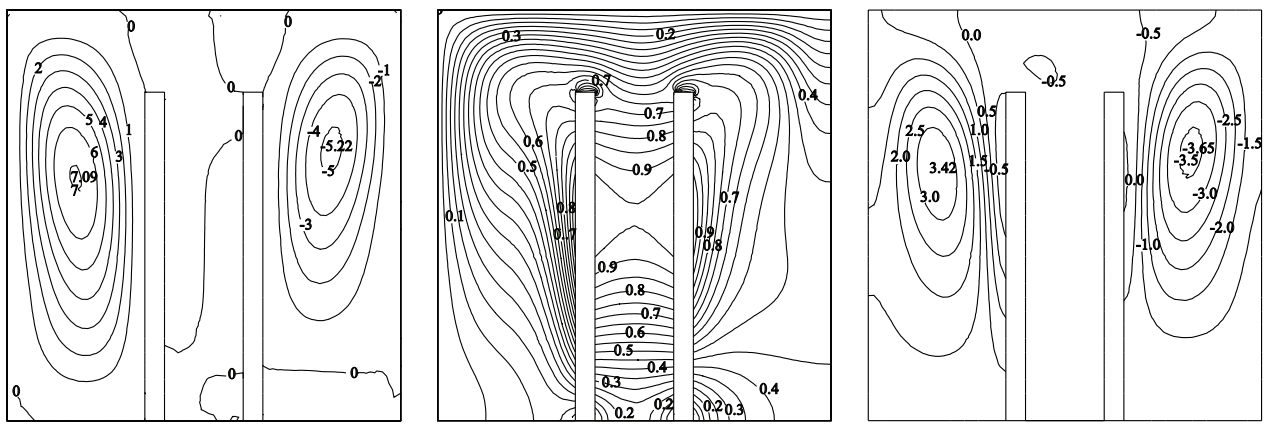

(c)

Figure 3: Streamlines(left), isotherms(center), heatlines(right) for $R a=$ $10^{5}, \mathrm{~s}=0.2$ and $l=0.8 ; D a=10^{-5}(\mathrm{a}), D a=10^{-3}(\mathrm{~b}), D a=10^{-1}(\mathrm{c})$

ble cells of streamlines are obtained for all Darcy numbers when the partitions are higher. Double cells of streamlines rotate in two directions due to natural convection, the left cell rotates in counter clockwise direction but the right cell 

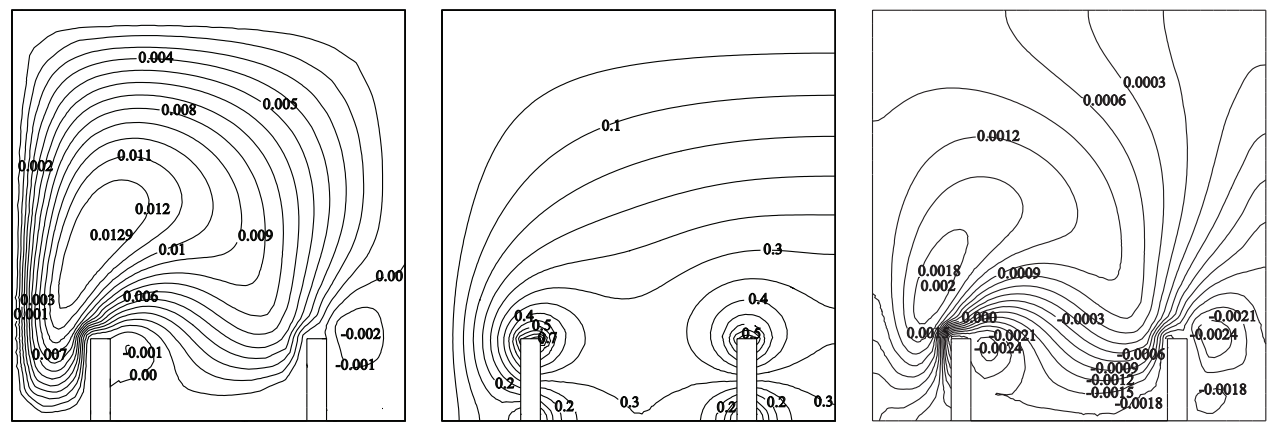

(a)
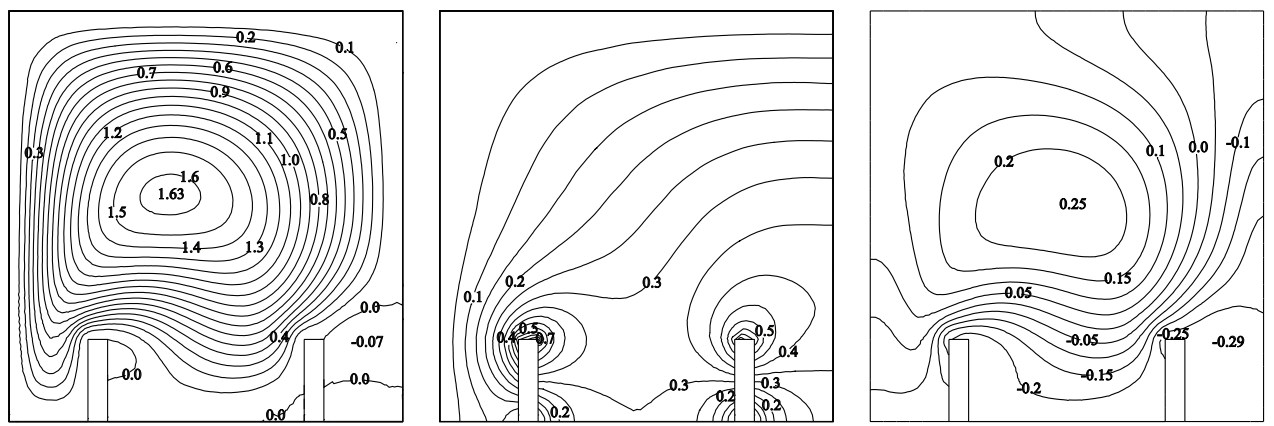

(b)
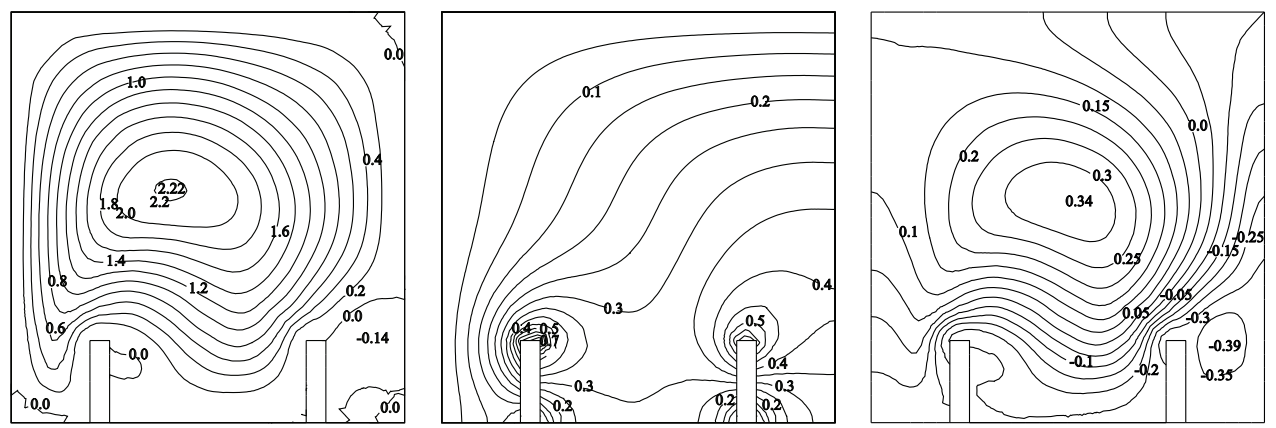

(c)

Figure 4: Streamlines(left), isotherms(center), heatlines(right) for $R a=$ $10^{5}, \mathrm{~s}=0.5$ and $l=0.2 ; D a=10^{-5}(\mathrm{a}), D a=10^{-3}(\mathrm{~b}), D a=10^{-1}(\mathrm{c})$

rotate in the opposite direction. The cells elongate parallel to the vertical wall due to the shallow geometry of the enclosure. The adjacent cell near cooled wall is bigger than the adjacent cell near insulated wall for all Darcy numbers. 

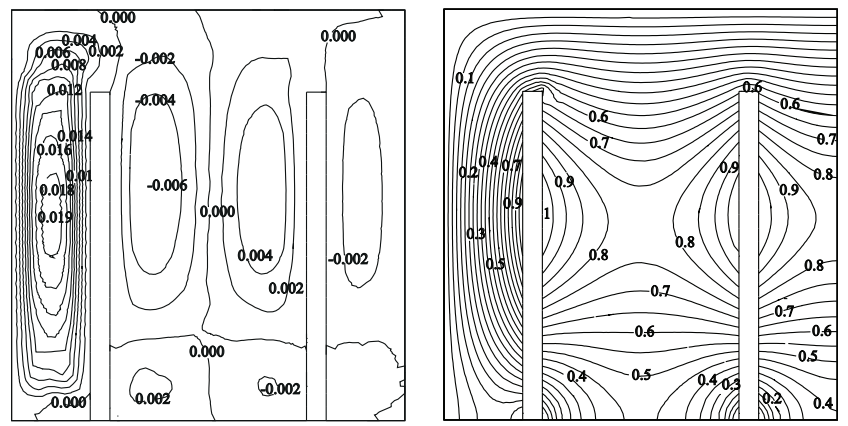

(a)
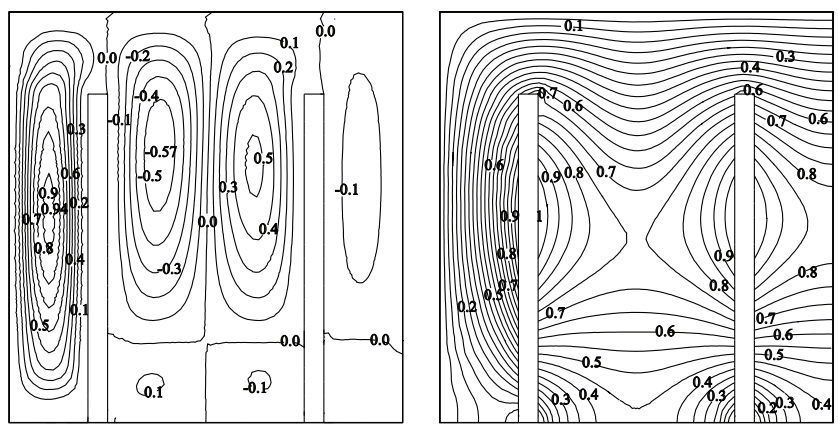

(b)
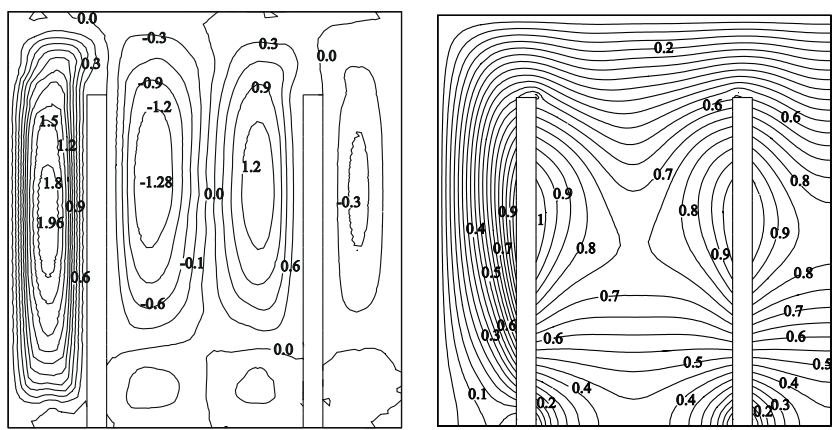

(c)
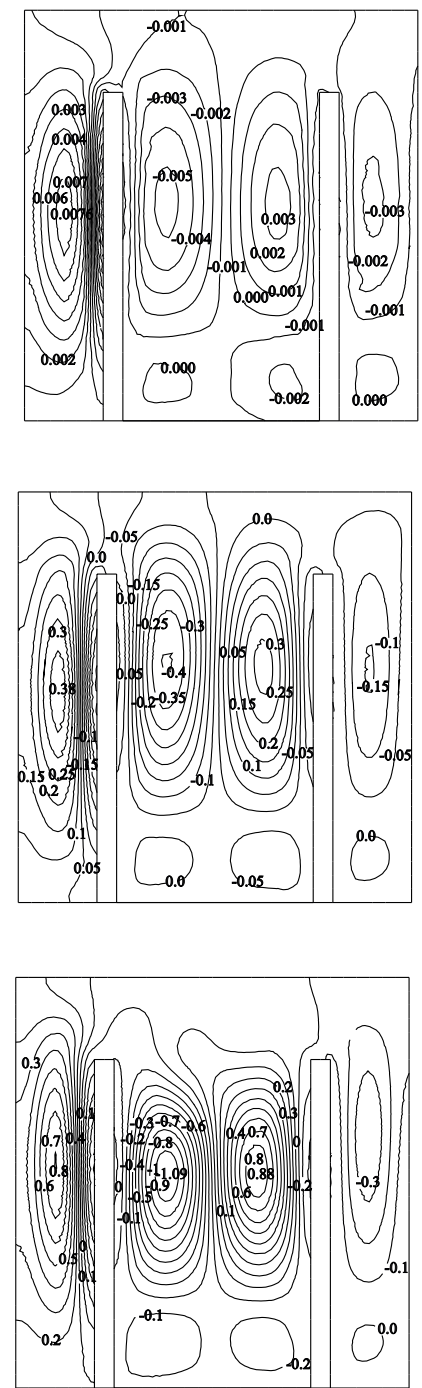

Figure 5: Streamlines(left), isotherms(center), heatlines(right) for $R a=$ $10^{5}, \mathrm{~s}=0.5$ and $l=0.8 ; D a=10^{-5}$ (a), $D a=10^{-3}(\mathrm{~b}), D a=10^{-1}$ (c)

The isotherms are shown on the second column of Figure 3. Isotherms are distributed almost parallel. At the height of the partitions from $0.3-0.8$, we can see that temperature distribution of upper half side is similar to lower half side 
in the region between two partitions. When Darcy number is increased, the periphery contours of isotherms deviate but the isotherms contours between the partitions are the same. For the heatines, there exist double cells rotating in different directions. Although The pattern of heatlines are similar to the streamlines, some contours of heatlines move to the walls of enclosure and the partitions. Moreover, the maximum value of streamlines and heatlines increase when the Darcy number value is increased.

Figure 4(a)-4(c) illustrate the streamlines(left), isotherms(center) and heatlines(right) contours of the numerical results for various $D a=10^{-5}-10^{-1}, R a=$ $10^{5}, s=0.5$, and the heights of two partitions are 0.2. It is clearly shown that the location of two partitions differs by Figure 2. For streamlines, we can see that the streamlines are single cell rotating in counter clockwise direction. The single cell is distorted from original shape by two partitions. When Darcy number is increased, the cells of streamlines expand and the maximum value increases. For the isotherms, it can be observed that the contours of isotherms are smooth curves. The contours of upper half for two partitions distribute on the top of the partitions while the contours of lower half disperse to the bottom wall of enclosure. Moreover, some contours of the isotherms move from the partitions into the right vertical wall. When the Darcy number is increased, the periphery contours are raised and deviated. In the case of the heatlines, the cell of heatlines circulates in counter clockwise direction. The pattern of heatlines is similar to the streamlines. However, some contours near the walls are not circle. The center of heatlines cell shifts close to the right vertical wall and both absolute maximum and minimum values increase when the Darcy number is increased. If we compare Figure 2, it can be observed that the trend for streamlines and heatlines are almost the same for each case. However, the streamlines and heatlines cells of Figure 4 are bigger than those of Figure 2. The contours of isotherms connecting between two partitions in the Figure 2 are more dense than those of Figure 4.

Figure 5(a)-(c) illustrate the streamlines(left), isotherms(center) and heatlines(right) contours of the numerical results for various $D a=10^{-5}-10^{-1}, R a=$ $10^{5}, s=0.5$, and the heights of two partitions are 0.8. For the streamlines, there are four cells rotating in two directions. The cell of the left side near the left vertical wall and the cell of the right rotating inside in the region between the partitions rotate in counter clockwise direction but the other cells rotate in clockwise direction. The contours of isotherms that occur from the heated partitions are smooth curves along the walls. The pattern of heatlines is similar to one of the streamlines except two cells close to the vertical walls in which some of their contours disperse toward the walls. If we compare Figure 3, the 
number of cells for streamlines and heatlines in Figure 4 is more than one in Figure 2 when the region between two partitions is wider. We can see that the pattern of isotherms is almost the same. However, the contours in region between two partitions differ from Figure 3 that the contours of isotherms connecting between two partitions of Figure 3 are more dense than those in Figure 5.

\section{Conclusion}

A numerical study is performed to examine natural convection in porous enclosure when the partitions are heated. Effects of the parameters such as Darcy number, Rayleigh number, location and height of two partitions are numerically investigated. The results and discussion are presented in previous section. Important conclusion of the results are as follows:

1. The values of the streamlines and the heatlines increase when Darcy number is increased, for all cases.

2. The partitions can be used to control flow field, temperature distribution and heat transfer.

3. When both partitions are fixed at 0.8 , double cells of streamlines are founded. Each cell rotates in different directions, the cell on the left-hand side rotates in counter clockwise circulation and the cell on the right-hand side rotates in clockwise circulation.

4. For isotherms, the contours that occur from heated the partitions are smooth curve. When the Darcy number is increased, the periphery contours deviate.

5. The direction and pattern of the heatlines are similar to the streamlines.

\section{Acknowledgment}

The authors would like to thank Department of Mathematics, Faculty of Science, Khon Kean University for computational resources in this research. This study is supported by Centre of Excellence in Mathematics, the Commission on Higher Education, Thailand. 


\section{References}

[1] D.A.Nield, A. Bejan, A. eds. Convection in Porous Media. second ed, Springer, New York (2006).

[2] D.B. Ingham, I. Pop, Transport Phenomena in Porous Media, Oxford, Pergamon (2005).

[3] J.N. Reddy, An Introduction to The Finite Element Method, McGrow-Hill, New York (1993).

[4] O. Aydin, A. Unal, T. Ayhan, Natural convection in rectangular enclosures heated from one side and cooled from the ceiling, Int. J. Heat Mass Transfer, 42, (1999), 2345-2355. doi: 10.1016/S0017-9310(98)00319-6.

[5] T. Basak, S. Roy, T. Pual, I. Pop, Natural convection in a square cavity filled with a porous medium: Effect of various thermal boundary conditions, Int. J. Heat Mass Transfer, 49, (2006), 1430-1441. doi: 10.1016/j.ijheatmasstransfer.2005.09.018.

[6] E. Bilgen, R.B. Yedder, Natural convection in enclosure with heating and cooling by sinusoidal temperature profiles on one side, Int. J. Heat Mass Transfer, 50, (2007), 139-150. doi: 10.1016/j.ijheatmasstransfer.2006.06.027.

[7] Y. Varol, H.F. Oztop, I. Pop, Numerical analysis of natural convection for a porous rectangular enclosure with sinusoidally varying temperature profile on the bottom wall, Int. Comm. Heat Mass Transfer, 35, (2008), 56-64. doi: 10.1016/j.icheatmasstransfer.2007.05.015.

[8] Y. Varol, H.F. Oztop, M. Mobedi, I. Pop, Visualization of natural convection heat transport using heatline method in porous non-isothermally heated triangular cavity, Int. J. Heat Mass Transfer, 51, (2008), 5040-5051. doi: 10.1016/j.ijheatmasstransfer.2008.04.023.

[9] P. Khansila, S. Witayangkurn, Visualization of natural convection in enclosure filled with porous medium by sinusoidally temperature on the one side, Appl. Mathematical Sciences, 97, (2012), 4801-4812.

[10] I. Dagtekin, H.F. Oztop, Natural convection heat transfer by heated partitions within enclosure, Int. Comm. Heat Mass Transfer, 28, (2001), 823834. doi: 10.1016/S0735-1933(01)00286-X. 
[11] E. Bilgen, Natural convection in cavities with a thin fin on the hot wall, Int. J. Heat Mass Transfer, 48, (2005), 3493-3505. doi: 10.1016/j.ijheatmasstransfer.2005.03.016.

[12] S.A. Nada, Natural convection heat transfer in horizontal and vertical closed narrow enclosures with heated rectangular finned base plate, Int. J. Heat Mass Transfer, 50, (2007), 667-679. doi: 10.1016/j.ijheatmasstransfer.2006.07.010.

[13] Y. Varol, H.F. Oztop, A. Varol, Natural convection in porous triangular enclosures with a solid adiabatic fin attached to the horizontal wall, Int. Comm. Heat Mass Transfer, 34, (2007), 19-27. doi: 10.1016/j.icheatmasstransfer.2006.09.004.

[14] A.B. Nakhi, A.J. Chamkha, Conjugate natural convection in a square enclosure with inclined thin fin of arbitrary length, Int. J. Thermal Sciences, 46, (2007), 467-478.

[15] K. Kahveci, S. Oztuna, MHD natural convection flow and heat transfer in a laterally heated partitioned encloure, European. J. Mechanics B/Fluids, 28, (2009), 744-752.

[16] Y. Varol, H.F. Oztop, Control of buoyancy-induced temperature and flow fields with an embedded adiabatic thin plate in porous triangular cavities, Appl. Thermal Engineering, 29, (2009), 558-566. doi: 10.1016/j.applthermaleng.2008.03.018.

[17] D. Bhanja, B. Kundu, Thermal analysis of a constructal T-shaped porous fin with radiation effects, Int. J. Refrigeration, 34, (2011), 1483-1496.

[18] S.H. Hussain, M.Y. Jabber, A.S. Mohamad, Influence of presence of inclined centered baffle and corrugation frequency on natural convection heat transfer flow of air inside a square enclosure with corrugated side walls, Int. J. Thermal Sciences, 50, (2011), 1799-1808. doi: 10.1016/j.ijthermalsci.2011.03.016. 